\title{
Bladder Trigone
}

National Cancer Institute

\section{Source}

National Cancer Institute. Bladder Trigone. NCI Thesaurus. Code C12331.

The triangular area in the bladder mucosa that is formed by the two ureteral orifices and the urethral orifice. 